\section{APPLIED PHYSICS}

\section{An Opportunity for EPS}

Next year, in the course of the Fourth General Conference at York, the EPS celebrates its tenth anniversary. Not surprisingly, the Society owed its inception to physicists engaged in the more academic sectors and in so-called "big science" where European collaboration in bodies such as CERN was an established fact. Nevertheless, among the pioneers was a handful of physicists who felt that the Society should also meet the needs of the applied physicist. The formation of an Applied Physics Division was discussed, but rejected. Such a Division would have emphasised the separation between pure and applied physicists, rather than encouraging them to mingle and share their problems and experience. Moreover, it would have assumed a clear-cut distinction between the two groups which is far from the truth; some excellent applied work is carried out in academic centres and many technological institutes and industrial laboratories legitimately have to carry out research of a basic character. As an alternative and more flexible measure, the Executive Committee set up an advisory body, and in January 1969 the Advisory Committee of Applied Physics and Physics in Industry (ACAPPI) met for the first time in Zurich.

The title of the Committee reflects the problem of interpreting its function; physics may be applied to other scientific and engineering disciplines, and also to the arts and humanities, but its most unequivocal applied role is in the manufacturing and public utility industries. However, a good watch-dog has to focus its attention, and so, in practice, the Committee has concentrated on certain main tasks :

(i) Introduction of applied aspects into appropriate EPS conferences.

(ii) Promoting coverage of the applications of physics in the EPS publications and the Europhysics journals.

(iii) Establishing and nurturing contacts with organizations and activities concerned with applied physics in Europe.

\section{First Task}

ACAPPI has met with most success in the first of these tasks, which it has so far invariably carried out in cooperation with one or more of the specialist subject divisions of the Society. The general principle followed, has been to suggest to conference organizers at a sufficiently early stage that talks already planned should be broadened to cover possible applications, or additional contributions should be solicited, fulfilling this bridging function but still within the main theme of the conference. Alternatively, applied symposia or workshops may be recommended to take place in juxtaposition with an otherwise largely basic conference. Representation of ACAPPI on the Conference Committee and cross-representation, particularly with the Condensed Matter and Quantum Electronics Divisional Boards have provided the mechanism. The implementation of this procedure is most evident in the triennial General Conferences; at the Third General Conference in Bucharest with its theme of Energy and Physics, ACAPPI played a substantial part in organizing sessions on the production, transport and storage of energy and also on the related materials problems. Similarly, looking ahead to York next year, ACAPPI has the main responsibility for the inter-Divisional Symposium on Modern Optics - a highly topical subject with an excellent balance between basic and applied aspects.

Recently, in close co-ordination with the Condensed Matter Division, ACAPPI has organized and held a Europhysics Study Conference on Luminescence Processes in Phosphors. This new venture, which is reported elsewhere in this issue (see opposite) attracted strong support; half the participants were from manufacturing industry and about a third from academic laboratories. It may not always be so easy to find a topic not already heavily covered, which has this particular combination of, on the one hand, considerable product signifiance and, on the other, difficult and incompletely solved basic problems.
However, there is certainly scope for a strictly selective promotion of conferences of this type, perhaps as an alternative to one or two of the regular rather over-exposed topics.

\section{Second Task}

The second of the tasks listed above is necessarily constrained by the relatively limited influence which the EPS can exercise at the present time on scientific and technical publishers in Europe. In practice, recommendations from ACAPPI via its representative on the Publications Committee have mainly concerned the applied physics coverage of journals seeking or already awarded the Europhysics label. The work is detailed and continuing, but it can only have a more substantial impact when progress has been made on wider issues of EPS publications policy outside the range of this article. Moreover, it has to be remembered that much of the best coverage of applied physics, particularly in the electrical and electronic fields, is naturally to be found in the wide range of reputable journals published by, or for, the engineering profession.

\section{Third Task}

The third of the main terms of reference of ACAPPI is the most difficult to implement; yet it provides the greatest scope for worthwhile action. How do we establish a reciprocal bond between the EPS and the centres of applied physics in Europe?

The essential first steps were taken by ACAPPI under the enthusiastic leadership of its first Chairman, O.G. Folberth. Address lists of applied institutions and their principal interests in relation to the EPS Divisional pattern were drawn up, which forms a valuable reference even though some European countries are still not covered. It may not be widely known that these lists are held by the Secretariat in Geneva and may be consulted on request. Additionally, a comprehensive survey was conducted, aimed at identifying what physicists working in or near the industrial sector could reasonably expect from EPS to encourage their greater support. Special attention was focussed on the Society's service to corporate bodies who had joined or were eligible as Associate Members. The conclusions are on record (EPN 3 (March 1972) 1) but within their inevitable limitations of practicality and lack of unanimity they mostly resolve into a wish for good information, pertinent conferences and discussion meetings, and 
greater mobility and interaction of physicists throughout Europe. Most of these require action by the Society as a whole, but ACAPPI has pursued the first two in particular. The Committee believes that without effective and demonstrably relevant activity on such matters, applied physicists will not become really active in the Society ; exhortations alone do not succeed.

Finally, it should be recorded that this is a personal statement by the retiring Chairman of ACAPPI. The incoming Chairman, J.-P. Hurault, and his fellow-members will steer their own course, but undoubtedly their objective will be the same: to ensure that EPS becomes as much the home for the applied physicist as it already is for his more fundamental colleagues. Success in this aim is surely a major challenge to the EPS at this time.

L.A.A. Thomas

\section{PARS COLLEGE TEHRAN - IRAN}

Regular faculty positions are available for solid state physicists and material scientists beginning in the Autumn of 1977. Duties will be divided between research and teaching at both graduate and undergraduate levels. Applicants should have a Ph.D. and an active interest in current research in order to supervise M.Sc. thesis projects. Priority will be given to those with laboratory experience in the following areas:

X-ray crystallography, N.M.R. studies, Mossbauer spectroscopy, Electron microscopy, Neutron scattering, Crystal growth, Low temperature physics, Physics of energy.

Send curriculum vitae, list of pubilcations and 3-5 letters of reference to:

\author{
Prof. Ali A. Zahedi-Moghadam \\ Chairman, Physics Department \\ Pars College \\ P.O. Box 3441 Tehran, \\ Tehran, IRAN
}

\section{Luminescence Processes in Phosphors}

\section{for}

\section{Cathode-Ray Tubes and Lamps}

\section{An ACAPPI - CMD Europhysics Study Conference}

At the end of March scientists from ten European countries, from Israel and the USA met at the National College of Food Technology, Weybridge in England for a three-day Europhysics Study Conference on "Luminescence Processes in Phosphors for Cathode-Ray Tubes and Lamps". This conference was organised within the EPS by ACAPPI and the Condensed Matter Division, the theme reflecting the Committee's view that the technologically important field of phosphor research is not one which is well served by conferences, particularly within Europe. It is also a field where a fundamental understanding of the basic materials physics is not yet well developed, and the opportunity for an interdisciplinary forum along the lines of the Gordon Research Conferences was especially welcome to many people. Of the 84 participants, 48 were from industrial laboratories, 26 from universities and related institutions and 10 from government research establishments.

The Conference comprised seven sessions, the theme of each being set by a one hour introductory lecture from the session chairman. This in- vited contribution was followed in each case by a small number of short submitted papers and finally by a substantial discussion period. The majority of sessions were designed to highlight particular aspects of phosphor operation, where present theoretical understanding is limited. Nowhere was this emphasis better illustrated than in the opening session on saturation effects in CRT phosphors led jointly by the Programme Chairman P.J. Dean and G. O. Muller. Saturation in II-VI phosphors can be reasonably explained by the low activator concentration producing optimum performance in these materials, but in high concentration $(\sim 1 \%) \mathrm{RE}$ phosphors a different explanation is necessary. A possible cause of saturation in RE materials is beaminduced heating, but recent work using materials with an internal "spectroscopic thermometer" in order to measure instantaneous temperature during the luminescence process, indicates that this is not the dominant factor at moderate drive levels in a CRT. There is some suggestion that the saturation may, at least partly, be the result of luminescence quenching through space-charge elec- tric fields generated by the incident electron beam. At the end of the introductory talk, Dean reviewed work on electric field effects on luminescence in semiconductors, and emphasised the importance of surface properties in controlling some of these field effects. The effects of phosphor surfaces on their performance was a theme taken up in a later session chaired by R.-H. Williams. Intuitively, one would believe that surface effects must be important in phosphors, which have a relatively large surface/volume ratio compared with most electronic materials, and yet the paucity of work in this area was immediately apparent. As the speaker suggested, this is an area ripe for development. However the difficulties should not be discounted, and in reviewing the properties of surface states and the commonly-used experimental techniques, Williams emphasised that a multi-technique investigation on both powder and single crystal material simultaneously, would be necessary to identify convincingly the relationship between surface properties and luminescence efficiency in phospor materials. Further progress in this area seems to depend upon the identification of suitable systems for study, and these unfortunately did not emerge at the Conference. Perhaps the answer is to be found amongst those materials of immediate technological interest as low-energy CRT phosphors, where surface effects are of paramount importance.

There were two sessions devoted to energy absorption, diffusion and loca- 